\title{
Developing Benchmarks For Prior Learning Assessment: The Case For Nurse Education
}

\author{
Malcolm Day, RN, University of Nottingham, UK
}

\begin{abstract}
This report discusses the results of a benchmarking study that examined how prior learning assessment (PLA) is conducted within UK nursing faculty and discusses how this might impact on the career of the PLA practitioner. A screening survey was administered to 66 UK Schools of Nursing. This initial survey identified a cohort of 22 experts and 12 novices from 34 Schools of Nursing who were actively involved in the practice of PLA. This cohort was subjected to a benchmarking survey to determine whether their practice complied, or did not comply, with international benchmarks for PLA. Respondents were asked to justify their responses by making additional written comments. These comments were further explored using focus group and depth interviews in order to identify emergent themes and categories, which were then subjected to analysis using modified grounded theory. This enabled the researcher to identify factors influencing PLA practice and how these might shape the career of the PLA practitioner. Methods of assessment were also identified - when optimal resources are available, the PLA practitioner usually adopts an assessment method that is based on the individual needs of learners, rather than the administrative requirements of the institution. These methods are holistic. They are also inclusive, rather than exclusive, or specific to, a competency or developmental approach to PLA. Finally, the importance of "bottom up" rather than "top down" or institutional approaches is justified as a mechanism for PLA policy development and the importance of emerging benchmarks in supporting the career life cycle of the PLA practitioner is also discussed.
\end{abstract}

Keywords: Assessment of Prior Learning; Prior Learning Assessment; Recognition of Prior Learning; APL Advisor; APL Assessor; Career of the PLA Practitioner

\section{WHAT IS PRIOR LEARNING ASSESSMENT?}

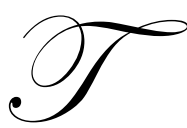

he term Prior Learning Assessment (PLA) includes Assessment of Prior Learning (APL). It also includes APCL or Accreditation of Prior Certificated Learning i.e. Learning for which certification has already been awarded. The term also includes Accreditation of Prior Experiential Learning (APEL) which refers to uncertificated learning gained through experience [1]. In the USA and Canada, the term PLAR or Prior Learning Assessment and Recognition is used [2]. The term Recognition of Prior Learning (RPL) is used in South Africa. [3].

The Canadian Association for Prior Learning [4] states that PLA is a systematic process that involves the identification, documentation, assessment and recognition of learning. This learning may be acquired through formal and informal study including work and life experience, training, independent study, volunteer work, travel, and hobbies and family experiences. This learning can be used towards the requirements of education and training programmes, occupational and/or professional certification. Challis [5] states that the process of PLA includes: the identification of learning, wherever it has taken place; the selection of that learning that is relevant to an outcome, career or occupation; demonstration of the validity and appropriateness of the learning; matching learning outcomes to those within a chosen accreditation framework; assessment of evidence against criteria to ensure validity of the claimed learning; and accreditation within a recognised accreditation framework. Although PLA has been in use UK nurse education for some time [2] it has assumed a new importance as the Nursing and Midwifery Council (NMC) has now indicated that up to $50 \%$ of a pre registration nursing programme can now be achieved by assessment of a learner's prior learning [6]. 
Harris [7] comments on the shifts in PLA practice that have occurred within the UK and acknowledges the significance of earlier work undertaken by Butterworth [8] who indicated that two contrasting models for PLA have emerged. Firstly, the credit exchange model. The learner identifies areas of a program they have achieved, and then offers evidence of these past achievements. Credit is awarded if the assessor and verifier agree that the evidence shows the necessary competence. Butterworth argues that the credit exchange model coincided with the introduction of National Vocational Qualifications. Harris [7] elucidates by stating:

In this (the NVQ) model, learning and reflection are rear grounded in favour of the candidate providing evidence of performance and achievement. The focus shifts to credentialising.

Secondly, Butterworth describes the developmental model, which emphasizes the use of documentary evidence supported by reflective commentary. The learner's reflection is supported by discussions with a tutor. The purpose of these discussions is to support the learner's personal and professional development. The assessor judges both the evidence and the reflective personal account within the portfolio before recommending that appropriate credit is awarded. Butterworth [8] explains that the developmental approach is based on a legitimate pedagogy for higher education as it assists the learner to undertake an analysis of their own practice and to increase their professional expertise. This view is supported by Anderson [9] who states the purpose of the developmental approach is to: “... inform and change the continuing learning process." It is also supported by Popova-Gonci [10] who in proposing building blocks for PLA communities in the USA states that we should: “...celebrate PLA as a learning process..."

Further, a study conducted by Swegers et.al. [11] identified two types of PLA portfolio the recognition portfolio and the acknowledgement portfolio. The recognition portfolio mainly fulfils a formative function, while the function of the acknowledgement portfolio is primarily summative. However, Swegers et.al [11] argues that the processes involved in building either type of portfolio are not mutually exclusive. This is interesting, as their work suggests that a more integrated approach to PLA is now emerging.

\section{WHAT IS BENCHMARKING?}

Benchmarking is a practice that allows a service to determine its standing within its field. Organizations use benchmarking to solve problems, plan and set goals, and improve processes. The Higher Education Funding Council for England or HEFCE [12] defines benchmarking as:

A process through which practices are analysed to provide a standard measurement ('benchmark') of effective performance within an organisation (such as a university). Benchmarks are also used to compare performance with other organisations and other sectors.

Benchmarking in health care has been in place for over a decade through the: "Essence of Care Project" which has now identified over a dozen benchmarks for care delivery including: privacy and dignity; food and nutrition; personal and oral hygiene etc. [13]. In this study, the practice of PLA in UK Schools of Nursing is compared with benchmarks for prior learning assessment developed by the Canadian Association for Prior Learning Assessment or CAPLA [4].

\section{THE RESEARCH PROBLEM}

Successive Government strategies for Higher Education have indicated a clear intention to expand student numbers and to increase participation rates by developing the credit based systems already operating within English Universities [14]. In 2004, the Quality Assurance Agency for Higher education (the QAA) developed PLA guidelines for faculties of higher education [15].These guidelines offered principles and prompts for universities undertaking PLA and complemented the higher education qualifications framework that had previously been published by QAA in 2001 [16]. Both of these frameworks are still in existence. However, a study by the National Institute for Adult Continuing Education (NIACE) in 2008 reported that PLA in Higher Education was still characterized by inconsistency and lack of coherence [17]. This is (perhaps) not surprising as the practice of PLA has not been developed, or refined, through a process of systematic enquiry. Rather, it has been based upon: 
"happenstance, coincidences and flukes of timing" [18]. Also, Scott [2] indicates that the number of empirical studies that test the assumption behind PLA practice is low. Further, Joosten-Ten Brinke, et.al. [19] indicated that PLA literature is mainly descriptive and in order to learn more about the quality of PLA it is important to put PLA on the empirical research agenda.

However, despite the apparent dearth of research based literature relating to the field of PLA it was felt that a brief review should undertaken in order to gain an overall impression of issues relating to PLA practice and (perhaps) to explain some of the findings of NIACE . This review identified what appeared to be significant tensions underpinning PLA work. These tensions focus on the relative merits of either a credit exchange model (Product) or a developmental model of PLA (Process). They have been categorised in Table One and have been used to develop an investigative framework for this study.

Table One: The Tensions Underlying PLA Practice in Higher Education (from Day, 2011 [20])

Objectivity versus Bias i.e. academics have higher expectations of PLA students than those who are attending taught courses, and are therefore biased in the way they assess non-institutional learning.

Equality versus Elitism i.e. Professions are now considering alternative forms of entry for individuals with vocational qualifications. There is a concern that this may lead to a drop in standards.

Internalization versus Alienation of learning i.e. there is a belief that PLA activity may become so focussed on meeting assessment outcomes that learners become alienated from the learning they have experienced. For example see: Popova-Gonci [10]

Quality versus Excessive surveillance i.e. the need to quality assure assessment outcomes must be balanced against the purpose of the assessment, as well as the desire for utility For example, see Andersson, [9].

Congruence versus Discord i.e. if academics cannot agree that PLA is a systematic and rigorous form of assessment (congruence) perhaps it is not surprising that students also have difficulty in understanding the process, and often have unrealistic expectations of PLA (discord).

It is the author's belief (and experience) that the role and responsibilities of the PLA Practitioner have developed in an uncertain and haphazard way and this uncertainty has added to the confusion and role strain experienced by university staff that have often had to undertake PLA activities in addition to their other duties. It is also the author's belief that PLA is being practiced in a less divergent way within UK Schools of Nursing than the literature suggests. Also, PLA practitioners have become quite pragmatic in order to resolve the tensions and subsequent discord that has underpinned their practice. This study sets out to evaluate the practice of PLA in UK Schools of Nursing and to challenge the assertion that PLA can only operate either as a product or a process.

Therefore, the fundamental idea behind this study is that guidelines for PLA practice can be developed by practitioners in order to minimise discord and achieve resolution or congruence. Therefore, this study uses a developmental and collaborative approach towards the establishment of benchmarks for PLA practice and asks the following research questions (1) can benchmarks for PLA practice in UK Schools of Nursing be agreed upon? (2) How might agreed upon benchmarks inform the career of the PLA practitioner?" The outcomes of the first research question have already been reported [20]. This article focuses on the outcomes of the second research question i.e. How might agreed upon benchmarks inform the career of the PLA practitioner?"

\section{THE SAMPLE}

Kennedy [21] has found that a lack of sustained funding and unclear institutional policies may significantly influence the practice of PLA. Therefore, if a clear and accurate picture of PLA activity is to be achieved it is important to determine whether practitioners: are supported by regular and sustained funding; working within established policy and procedure for PLA; and process significant numbers of PLA candidates. These essential requirements were adopted as inclusion criteria for this study and an initial screening survey was sent to Heads of 
Schools of Nursing in England, Northern Ireland, Scotland and Wales ( $\mathrm{n}=66)$ in order to identify a sample that met these inclusion criteria.

The returns from the screening survey identified a sample of 22 practitioners who actively processed PLA candidates; were supported by continued funding for PLA work; and who worked within established policy and procedure for PLA. This cohort was identified as "Expert" practitioners. Those who did not meet the inclusion criteria were included as "Novices " $(\mathrm{N}=12)$. There were no responses from Scotland.

The total number of participants included in the study was 34 . This was limited by application of the inclusion criteria. However, it was later found that there was no significant difference between the responses from experts and the responses from novices - suggesting (perhaps) that a larger sample could be drawn from the field if this study was to be replicated.

\section{ETHICAL ISSUES}

None of the participating institutions required a submission to a research ethics committee (REC) for approval. This is in line with current UK guidelines for research governance, which state that activities which are not research e.g. service evaluation, and research involving NHS staff recruited by virtue of their professional role does not require REC approval [22]. However, many writers including Motaung [3] stress the importance of PLA as an agent for democracy and social change. Therefore, it was felt necessary to develop ethical guidelines that supported these key principles. In particular, attention was paid to: the informed consent of participants; the right of participants to "opt out" of the study; and non -disclosure of information to third parties. For example, some responses in this study are reported anonymously in order to maintain institutional confidentiality and protect the individual's identity.

\section{THE BENCHMARKING SURVEY}

The benchmarking survey was based on the questionnaire developed for the National Canadian PLA Bench marking study [4]. This was tested for face validity and content validity with 17 practitioners who were a mix of expert and novices. Each was asked to comment on the structure of the benchmarks, and the time it took to complete the questionnaire. Those who were consulted felt that the questionnaire items were generally representative of PLA functions in the UK. Feedback also indicated that the PLA Adviser and the PLA Assessor roles were similar to those practiced within UK faculty. With regard to the clarity, structure and time taken to complete the questionnaire, no difficulty was reported with language and all questionnaires were completed within a reasonable period of time.

All of the items from the original Canadian survey were subsequently retained and included in the main UK survey, which was administered to Experts $(n=22)$ and Novices $(n=12)$ from 34 Schools of Nursing Each were asked to consider whether the benchmarks accurately described their current practice. They were asked to indicate "Yes," (it did), "No," (it did not), or if they were "Not Sure." Respondents were asked to justify their response by adding comments and to make relevant changes to the language used in the benchmarks. Twenty-one questionnaires were returned by the stated deadline, an overall response rate of $61 \%$. Thirteen questionnaires were returned by Experts. Eight questionnaires were returned by Novices. One novice indicated that he/she was not involved in nursing education - his/her response was discarded. Five experts (23\%) left the study before they completed the questionnaire. Three left because of pressure of work. Two left due to changes in role. All non- respondents were contacted by E-mail and asked to give a reason for not returning the questionnaire. The following reasons were given (1) pressure of work; (2) changes in role; and (3) concern about their own expertise.

A bivariate analysis of responses to the benchmarking survey showed that both Experts and Novices agreed that the functions and activities contained within the bench marked items were an accurate description of their role (Table Two). Therefore, it was decided to deal with qualitative data emerging from either group in the same way. 
Table Two: Newly Emerging Benchmarks for PLA Practice (from Day [20])

Key Purpose. The key purpose of the PLA Practitioner in UK Schools of Nursing and Midwifery is to: Review progress and/or assess achievements; so that individuals and organisations can achieve their personal development and/or education and training objectives. This includes assessment of individuals for academic credit and professional certification. The main functions and activities of the PLA Practitioner's role are to:

Function 1 - Prepare The Individual For Assessment. This includes the following activities:

- Help the individual to identify relevant learning outcomes

- $\quad$ Agree to and review an action plan for demonstration of prior learning. The action plan may be a verbal or written agreement between the PLA practitioner and the learner. It may also take the form of a learning contract.

- $\quad$ Help the individual to prepare and present evidence for assessment.

Function 2 -Assess The Individual. This includes the following activities: This may include the following activities:

- $\quad$ Progress formative assessment activities and judge evidence and provide feedback. Formative assessments are designed to provide learners with feedback on progress and inform development, but do not contribute towards the overall assessment [23]

- $\quad$ Contribute to making a summative assessment decision using differing sources of evidence and provide appropriate feedback. Summative assessments “provide a measure of achievement or failure made in respect of a learner's performance in relation to the intended learning outcomes of a programme of study [23]

- $\quad$ Contribute to making a summative assessment decision using differing sources of evidence and provide appropriate feedback.

NB. PLA Practitioners may carry out both of the above functions

A qualitative analysis of the additional comments received during the survey also indicated that practitioners appeared to combine credit based (product) and developmental (process) approached to meet the individual needs of the learner, as well as the demands of the workplace. For example one expert commented:

The evidence required will depend on the size of the credit claimed, the level, the course against which the claim is made and the claim itself- whether APCL or APEL or both combined. Thus each situation has to be prepared and evidence individually.

Also, from the comments received, practice did not appear to be determined by any particular learning theory. Rather practice appeared to be context dependent and influenced by: time and resources and university regulations. For example, one expert commented:

In our circumstances with confederation contracts, candidates only find out a few weeks before the commencement of a course that they are attending, therefore our schema is often time limited.

Table Three summarises the categories and themes emerging from the additional comments received from the benchmarking survey of practice. These were explored further using focus group work and depth interviews in order to verify or refute the comments emerging from the benchmarking survey.

Table Three: Factors Influencing PLA Practice: Results from the Benchmarking Survey of Practice

C

O Time and Resources

$\mathrm{N}$

$\mathrm{T}$

E

$\mathrm{X}$ Individual Learning Needs

$\mathrm{T}$

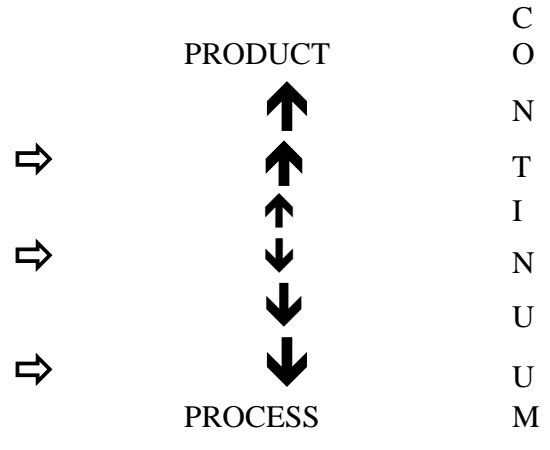




\section{THE FOCUS GROUP}

A focus group was conducted with 6 informants from the north of England, and 4 from the South of England making a total of 10 informants. Each of these participants had completed the bench marking survey. Each was provided with an activity sheet to complete prior to the focus group meeting. The activity sheet included the following questions: (1) what are the factors which might influence your approach towards PLA? (2) How might external factors influence your approach to PLA? (3) How might internal factors influence your choice of approach? Participants were asked to report back on their responses to the activity sheet and their discussions were audio taped. The tapes were transcribed and fed back to participants for comment. The transcripts were then compared with the themes that had emerged from the survey of practice (Table Three). This enabled the researcher to corroborate, and then further develop emergent themes, and to identify any gaps in data collection. For example, much of the group discussion focused on factors influencing practice with few specific examples given of how practice had changed. Therefore, it was necessary to draw out specific examples of any changes in practice during the depth interviews.

\section{DEPTH INTERVIEWS}

The interviews were conducted with participants who were unable to attend the focus group. This included one from SW England, and 3 from SE England. A total of 4 participants. Each had received regular project updates, and had been provided with a list of questions prior to the interview. The following questions were asked: (1) how has the availability of time and resources impacted on your practice? (2) How have university regulations impacted on your practice? (3) Have your methods of assessing prior learning changed in any way. Please give one specific example? (4) Practitioners in this study have indicated that they utilise credit based and developmental approaches to PLA. Where would you place yourself on this continuum? Interviews were audio taped. The tapes were transcribed and fed back to participants for comment. No further responses were received.

Participants who took part in the focus group and depth interviews had previously completed the screening survey, and the benchmarking survey of practice. Each of these participants contributed to, and received, regular project updates. Each had also been provided with a list of questions prior to their participation in a focus group or depth interview. This approach to data collection is highly valued by qualitative researchers who stress the need to develop a theoretical sensitivity towards data collection as this facilitates discrimination during the coding process [24].

\section{DATA ANALYSIS}

The following approaches to data analysis were undertaken. Firstly, comments emerging from the initial survey were examined to explain individual differences in practice (Table Three). Themes emerging from this initial analysis were used to construct questions for focus group activities and depth interviews. Secondly, data emerging from the focus groups and depth interviews was subjected to the analytical techniques described by Strauss and Corbin [24].This involved the following activities: (1) the development of categories or codes based on the similarity or dissimilarity of content; (2) a comparison of each incident with the category to determine if each incident fitted; (3) an examination of categories for uniformity and any differences; (4) a review of the literature to see how well the findings fitted with existing research; and (5) identification of a conceptual schemata which accounted for most of the relationships or patterns that had been observed. The categories and themes that emerged from this analysis are reported in Table Four. 
Table Four: Categories Emerging from Depth Interviews and Focus Groups Work

Category One: Influencing Factors:
Theme (a): University Regulations:
Empowerment
Initiation
Adjustment
Adaptation
Resolution
Internalisation.
Liberation
Theme (b): Time and Resources:
Intensification
Academic Gate keeping
Academic Rigour
Role strain
Role conflict
Nailing Colours to the Mast
Attrition
Building Capacity
Expert

Category Two: Assessment Methods:

Theme (a): University Regulations: Theme (a): PLA as a Product:

Empowerment

For specific credit

Products from work

Transcripts

Certificates

Assignments

Theme (b): PLA as a Process:

For general credit

Reflective writing

Whole person

Self assessment

Profiling

Theme (c): A continuum for PLA practice

For specific and general credit

Certificated $\underline{\underline{a n d}}$ experiential learning

PLA Workshops

Individual Profiling

The categories and themes outlined in Table 4 enabled the researcher to construct a schema that best describes the activities of the PLA practitioner in UK Schools of Nursing (Table Five).

Table Five. A Schema for PLA Practice in UK Schools of Nursing

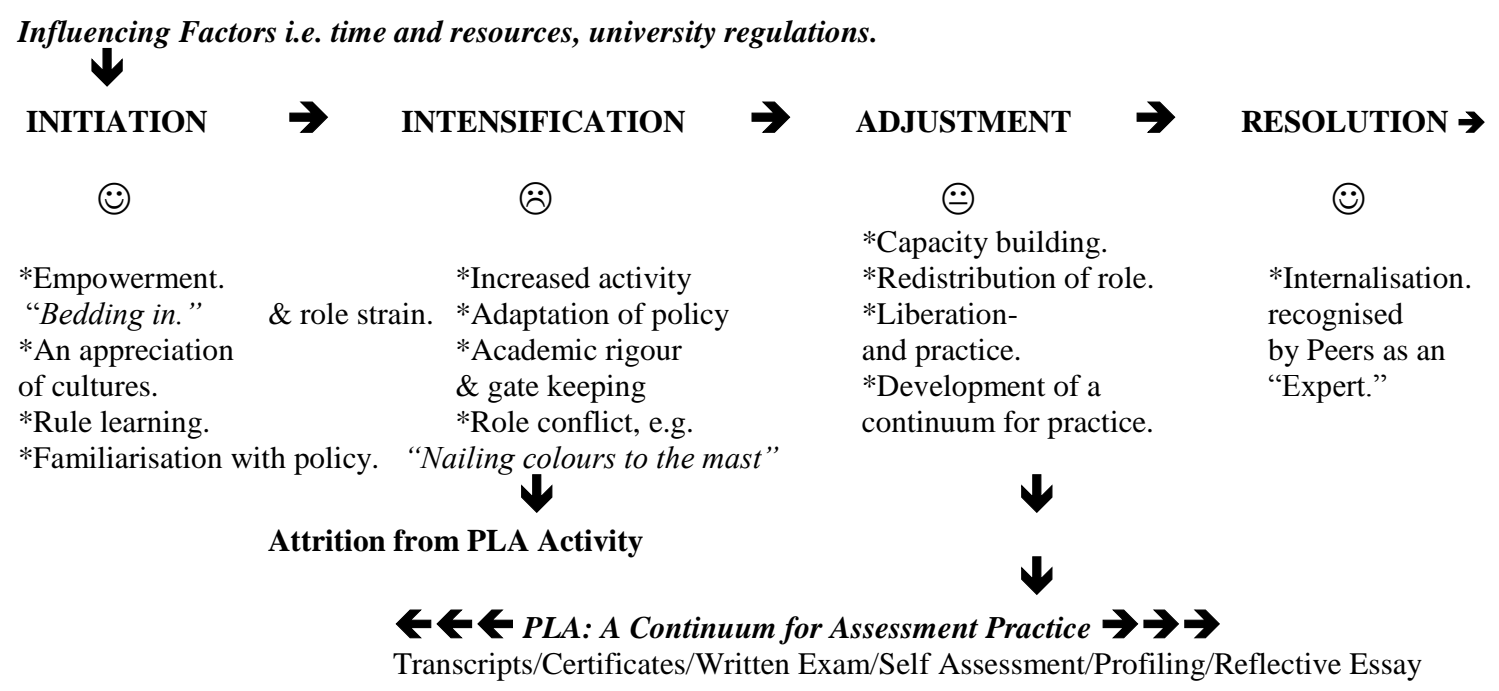

\section{RESULTS}

1. The Holistic Practice of PLA in UK Schools of Nursing

The practice of PLA can be described as a continuous cycle of: initiation, intensification, adjustment and resolution during which attempts are made to resolve the tension existing between the amount of time and resources 
available, and choice of assessment method (Table 5). For example, during initiation a period of "bedding in" occurs and an appreciation of cultures takes place. For example, one practitioner reported:

I would have to say when the Institute of Health Studies went into the university, it was accepted that we were different, and in many instances we worked outside of university regulations. That seemed to be perfectly acceptable to the university.

During periods of increased demand or intensification novice practitioners may experience role strain, and role conflict. This may precipitate a change in role. For example, participants indicated that they had a multifunctional role. This often gave rise to conflicting commitments:

I'm allocated time by my job description and being an admissions tutor this has meant that I continue to teach. There are no extra PLA advisers being paid, and there has been no change to my working week....

Interviewee S.E. England

There was also evidence that academic gate keeping had contributed towards the conflict experienced by practitioners. For example: "I have got staff saying that we are cheapening them and that we are devaluing the teaching that they do"

Focus Group Participant North of England

However, perhaps the best example of academic gate keeping emerged from the following narrative. It concerned the proposal that "listed competencies" be used as possible outcomes for PLA:

If you adopt a developmental approach (emphasis) and develop your curriculum in terms of ... well... what I would call a competency list... (noise from rest of group)... well, they (competencies) do exist... (laughter)...

Focus Group Participant. North of England

The following response was received:

But surely, that's why the university, THE (emphasis) university curriculum...shock, horror... (apparent cynicism) ... has introduced ENQUIRY (emphasis) based learning?"

Focus Group Participant North of England.

It appeared that these two participants were rehearsing the arguments put forward by Butterworth [8] in her analysis of credit based versus developmental models for PLA. Further, it appeared that each of these participants was demonstrating to others where their allegiances lay within this dichotomy. In effect they seemed to be: "Nailing their colours to the mast." (Table 5).

During the adjustment phase roles are redistributed, and attention is paid to capacity building; regulations, policy and procedure are adapted, and a continuum for practice emerges (Table 5). For example one interviewee from SW England indicated:

So initially, we worked outside university regulations that was accepted, it didn't hold us back. Now we have changed university regulations to accommodate all the changes that the institutes are experiencing. We push boundaries within the institute, and I changed university regulations the following year to reflect that.

Also:

Last year I managed to persuade them (the university) to let us use APEL at Masters Degree level as well. We were the first School to do that. So in a way we lead and the university regulations haven't been a problem.

Interviewee. S.W. England

This phenomenon can be described as an adaptive activity, undertaken to resolve issues relating to increased demands for intensification whilst still attempting to maintain some degree of academic rigour. 
Adjustment is followed by a period of resolution (Table 5) where PLA functions become internalised and practitioners feel liberated as their expertise is recognised by peers. For example, one practitioner reported:

The combination of my evolving role and the evolving role and expertise of the staff within the NHS Trusts means that time and resources have been made available for the students. And that has meant that being recognised as experts within the field, we've been further enabled to take the process forward. And I would say that has had a huge impact (emphasis) on our practice of PLA.

Finally, when optimal resources are available, the PLA practitioner usually adopts an assessment method that is based on the individual needs of learners, rather than the administrative requirements of the organisation. These methods are holistic and include the use of transcripts and certificates, as well as the use of profiling and reflective essays. They are inclusive, rather than exclusive, or specific to, a product or process based approach to PLA. For example, one practitioner from the North of England reported:

The actual notion of the portfolio is actually useful for new learners coming onto degree a programme. Self assessment, action planning, reflection, all of these fit very happily within portfolio assessment.

This finding is supported by the early work of the English National Board for Nursing Midwifery and Healthy Visiting (the predecessor of the current UK Nursing and Midwifery Council) [25] who confirmed that: " $A$ model of $A P(E) L$ is in use which appears to be halfway between APL and APEL." It is also consistent with the findings of Johnson [26] who (later) stated that an "all-through" or holistic model of PLA was in existence, and is supported by the work of Swegers et.al. [11] who describe an integrated approach to portfolio development. It also reflects the NMC's recent change in policy, which no longer differentiates between the practices of APL or APEL.

2. How emergent benchmarks may inform the career of the PLA practitioner

During the early stages of their career practitioners are initiated into the rules and regulations pertaining to PLA practice. It is possible that during this phase the benchmarks (Table 2) will provide greater direction for the novice practitioner. For example; one anonymous respondent indicated that the benchmarks will help: "...organisations identify how practitioners should be prepared for their role and ensures consistency in approach."

During periods of intensification practitioners may experience role strain or role conflict, which may result in attrition from PLA activities. Attrition could be minimised by adopting the benchmarks in order to gain greater clarity regarding the role of advisor and assessors For example, an anonymous respondent indicated: "Benchmarks can provide fairly explicit and externally accessible statements that should facilitate quality assurance ..."

The explicit nature of the benchmarks (Table 2) will enable faculty managers to accurately assess the extent and duration of PLA activities, so that appropriate resources can be made available within the institution to support PLA activity, thereby minimising the risk of practitioner attrition. The benchmarks may also be useful in quality assuring the PLA process as they will provide a common approach towards assessment, which is both consistent and transparent.

During the adjustment phase of the practitioner's career, roles are redistributed and attention is paid to capacity building. During this phase, regulations, policy and procedure are adapted, and a continuum for PLA practice emerges. For example, one anonymous respondent indicated:

...benchmarks serve to advance the self-awareness and reflexivity of practitioners. By encouraging practitioners to probe, reflect on and improve they can help to build up a consensual body of values, criteria and ways of doing things.

This respondent captures the dynamic and reflective nature of the benchmarking process and how this might serve as a basis for further development during the adjustment phase of the practitioner's career. 
During the resolution phase PLA functions become internalised by the practitioner. During this phase practitioners feel liberated as their expertise is recognised by peers. For example a PLA novice thought that the emerging benchmarks would: "... enable practitioners to function with a degree of confidence and ensures consistency in all institutions signed up to the benchmark."

The reader's attention is drawn to the suggestion (here) that there may be a relationship between the use of benchmarks for practice and the ability to practice in a confident manner. In this sense, the agreed benchmarks could become indicators for success.

\section{TRUSTWORTHINESS}

Babbie and Mouton [27] outline strategies used in social research to ensure "Trustworthiness". These include: credibility; transferability; dependability and confirmability.

In this study, strategies to achieve credibility include the use of: research methods that have already been tried and tested [4]; informants from different geographical regions; and multiple research methods such as survey, focus group and depth interviews (triangulation). Tactics to ensure the honesty of informants were also developed e.g. the use of activity sheets and iterative questioning during focus group and depth interviews. In addition: informants were asked to check transcripts for accuracy, while the results of the study were presented for discussion and peer review at conference [28].

Also, with regard to credibility, a comparison with previous literature has been made to test interpretations and emergent theories. For example, the emergent career pathway of the PLA practitioner is consistent with the literature on the: "Career Life Cycle" and there are strong comparisons to be made between the outcomes of this study and the work of Steffy et.al. [29] who have identified the Career Life Cycle of the professional teacher i.e. from: novice; apprentice; through to expert. This finding is of great interest as it identifies a possible underpinning theory for this study, which will be the subject of a further and more detailed report.

Strategies to achieve transferability and dependability include: a detailed explanation of emergent models for practice, this has allowed for comparisons of PLA practice to be made; and a detailed account of the sampling framework and an in-depth methodological description has been given to allow the study to be repeated. It is accepted that sample size was restricted by the application of inclusion criteria and that a larger sample could have been be identified had these criteria not been applied. Nevertheless, this work is representative of PLA practice within a significant number of UK Schools of Nursing, with the exception of Scotland.

Finally, confirmability has been achieved through: the use of triangulation; an account of the researcher's beliefs and assumptions about the nature of the research problem; and the use of tables and diagrams to provide an "audit trail" of activities and findings as they have emerged.

\section{CONCLUSION}

A quantitative analysis of data emerging from a benchmarking survey of PLA practice has confirmed that 21 PLA practitioners from 34 UK Schools of Nursing (excluding Scotland) have agreed upon benchmarks for PLA practice (Table 2). In addition, data emerging from this study indicates that PLA Practitioners within UK Schools of Nursing might utilise either a product or a process based approach towards PLA. There is also evidence to show that some PLA Practitioners utilise both product and process based approaches towards PLA - this finding suggests that a continuum for PLA practice is in existence. Within this continuum, PLA practitioners combine both product and process methodologies in an inclusive or holistic way to meet the individual needs of the learner, as well as the demands of the workplace. Thus, PLA methodology is not pre- determined by any particular learning theory or ideological stance, as suggested in the literature. Rather, it is context dependent and is influenced by the needs of the individual student; the time and resources that are available; and university regulations.

This study has also found that the career of the PLA Practitioner progresses through a number of significant phases including: initiation; intensification; adjustment; and resolution. Successful progression through each of these phases is dependent upon the influence of university regulations, the time and resources available and the 
approaches taken towards PLA, which may include a product and process based approache towards assessment. Practitioners, who are unable to resolve the tensions that exist between university regulations, and the time and resources available, withdraw from practice. For example, in this study a $23 \%$ attrition rate has been recorded. Practitioners that achieve a resolution do so by modifying the rules and regulations of the university, building capacity for resources and delegation of PLA practitioner roles. As a consequence of this adaptive behaviour a more inclusive or holistic approach towards PLA emerges.

Further, this study has found that a holistic approach is supported by a continuum for PLA practice, which identifies a typology of assessment methods associated with a product or a process based approaches towards prior learning assessment. For example, product based approaches include: the use of transcripts, certificates, and products from the work place; while process based approaches include: self assessment, profiling, and the use of reflective essays (Table 5). When using a holistic approach, the PLA practitioner will combine a product and a process based approach in order to generate evidence for specific and general credit.

Individuals who participated in this study have indicated that the emergent benchmarks for PLA will assist the PLA Practitioner in transition from novice to expert. In particular, the emergent benchmarks will: ensure that assessment of prior learning becomes a defensible process; improve accountability and transparency during the assessment process; assist education managers to identify what is possible, what is feasible, and what is acceptable for PLA practice; ensure consistency of approach towards assessment; provide a common understanding and communication between stakeholders; and protect the rights of students and assessment service users. Also, the benchmarks emerging from this study can be used to develop guidelines that might be used by the PLA Practitioner during his or her transition from novice to expert. These guidelines include: giving advice and guidance about PLA to learners; and assessing and making an assessment of a student's prior learning (Table 2).

Of course, the use of standards setting in higher education is highly controversial and is anathema to many academics as it has (in the past) been regarded as a form of social control, and has therefore been considered as a potential threat to academic freedom [30]. More recently, these concerns have been expressed by some academics as an increased demand for performativity [31]. However, it is my belief that there is a case for using the benchmarking process as an adjunct to professional development. This point has been well made by one participant in this study who stated: "Benchmarks serve to advance the self-awareness and reflexivity of practitioners..."

In this study, knowledge derived from practice has identified benchmarks for PLA that are underpinned by a common set of values and beliefs about the nature and purpose of prior learning assessment. It is possible that the emergent benchmarks could be used as a focus for the development of nurse teachers who are involved in undertaking PLA activities. This will ensure that the PLA process becomes more transparent, open and explicit; and will enable practitioners and their managers to signpost the changing resource requirements for PLA capacity building during the critical phase of adjustment. This in turn, will ensure that PLA practitioners are adequately supported during their transition from novice to expert, and may well assist in minimising practitioner attrition.

However, there is a more radical view of what professional development might mean for the teacher within higher education, as expressed by Sachs [32] in her politically motivated account of the: "Activist Teacher." For example, Sachs describes how teachers can resist the effects of performativity in order to develop their professional autonomy. Further, Sachs argues that teachers should take ownership of their profession by creating their own standards, and creating their own milestones for continuing development. With these points in mind, it is possible that emergent benchmarks (Table 2) can be used as a mechanism for professionalising PLA activities undertaken by teachers within the university sector. Previous attempts to do this have included the development of a code of practice for PLA - see SEEC [33]. However the SEEC Code of Practice appears to be more institutionally focused rather than pedagogically focused. Therefore, it is possible that that the benchmarks for PLA that have emerged from this study can be adopted as a pedagogical code of practice for nurse teachers who perform PLA activities within Schools of Nursing. This will provide a framework for practice that is based on a common set of values and beliefs about the nature and purpose of prior learning assessment that has emerged from the reflective (and collective) experience of PLA practitioners. 
However, it is possible that the emergent benchmarks may not have applicability for every professional group within the university, particularly as the sample for this study is restricted to the field of Nursing. Therefore, it is arguable that the outcomes of this study can only be applied to this particular (or similar) discipline within higher education. However, given the lead that Schools of Nursing have taken in the development of PLA; and the influence that practitioners within Schools of Nursing have had in developing PLA policy and practice [26] there is some evidence to suggest that the benchmarks and guidelines emerging from this study have a degree of applicability to other disciplines.

Of course, it is possible that there may be some cultural or philosophical barriers that could impact upon the implementation of the emergent benchmarks as a code of practice. Therefore, it is recommended that disciplines outside the field of health care undertake a thorough and systematic review of these, prior to their adoption. For example, Harris [34] suggests that it is critical for university departments to review their beliefs and assumptions concerning the nature of knowledge and associated mechanisms for teaching, learning and assessment prior to implementing any PLA activity. The systematic and analytical approach to PLA capacity building advocated by Harris will ensure that the PLA benchmarks and guidelines that have emerged from this study will be implemented in a way that is culturally sensitive to the needs of the organisation as well as the professional development needs of the university lecturer.

\section{AUTHOR INFORMATION}

Malcolm Day RN, B.Ed., M.Ed., M.Phil., FIfL., FHEA. is a Lecturer in Adult Nursing and PLA Advisor at the School of Nursing and Midwifery, University of Nottingham, England. E-mail: Malcolm.day@nottingham.ac.uk

\section{REFERENCES}

1. Day, M .2002. Assessment of Prior Learning. A Practitioners Guide. Nelson Thornes. Cheltenham.

2. Scott, I .2010. Accreditation of Prior Learning in pre-registration nursing programmes. Nurse Education Today 30, 438-442.

3. Motaung, J. 2009. The 'nuts and bolts' of prior learning assessment in the Faculty of Education of the University of Pretoria, South Africa. Perspectives in Education, Volume 27(1), 78-84.

4. Canadian Association for Prior Learning Assessment (CAPLA). 2000. Developing Benchmarks for Prior Learning Assessment. Peace Tree Printing, Ontario.

5. Challis, M. 1993. Introducing APEL. Routledge, London.

6. Long, G. 2010. NMC requirements, guidance and advice for accreditation of prior experiential learning (APEL) in new pre-registration nursing programmes. APEL Guidance 050710. Nursing and Midwifery Council, London.

7. Harris, J. 2004. Introduction and Overview of Chapters. Chapter 1, IN Andersson, P; and Harris, J. Retheorising the Recognition of Prior Learning. NIACE, Leicester.

8. Butterworth, C. 1992. More than one bite at the APEL: contrasting models of accrediting prior learning. Journal of Further and Higher Education. 16 (3) 39-51.

9. Andersson, P, 2006:34. Different faces and functions of RPL: an assessment perspective. Chapter 2, IN: Andersson, P; and Harris, J. Re-theorising the Recognition of Prior Learning. NIACE, Leicester.

10. Popova-Gonci, V. 2009:42. All Work and No PLA Makes Jack a Dull Boy, The Journal of Continuing Higher Education, 57 (1) 42 -44.

11. Sweygers, A. et.al. 2009. Portfolios for Prior Learning Assessment: Caught Between Diversity and Standardization. The Journal of Continuing Higher Education, 57 (2) 92 -103.

12. Higher Education Funding Council for England (HEFCE). 2010. About us: Glossary, available at http://www.hefce.ac.uk/aboutus/glossary/glossary.htm, updated 8 November 2010, accessed 27 January 2011.

13. Department for Health 2010. Essence of Care. The Stationery Office.

14. Department for Education and Skills. 2003. The Future of Higher Education. Creating Opportunity, Releasing Potential, Achieving Excellence. White Paper. CMM 5735

15. QAA. 2004. Guidelines for the Accreditation of Prior Learning. QAA 064 09/04. Quality Assurance Agency for Higher Education. Gloucester. 
16. QAA. 2001. The framework for higher educational qualifications in England, Wales and Northern Ireland. Quality Assurance Agency for Higher Education. Gloucester.

17. NIACE. 2008. Accreditation and Recognition of Prior Experience and Learning JISC Funded Project, July 2008. National Institute for Adult Continuing Education. Leicester.

18. Evans, N. 2000:49. The Evolution of AP(E)L in England. in Evans, N. (Ed). Experiential Learning Around the World: Employability and the Global Economy. Jessica Kingsley, London.

19. Joosten-Ten Brinke. D. et.al. 2008. The quality of procedures to assess credit prior learning: Implications for design. Educational Research Review 3. 51-65

20. Day, M. 2011. Developing Benchmarks for Prior Learning Assessment. An Exploratory Study. American Journal of Health Sciences. 2 (2).

21. Kennedy, B 2003. A Spring 2003 Snapshot. The Current Status of Prior Learning Assessment and Recognition (PLAR) in Canada's Post Secondary Institutions. Canadian Association for Prior Learning Assessment.

22. DH Research and Development Directorate (England); National Institute for Social Care and Health Research (Wales); Chief Scientist Office (Scotland); R\&D Division, Public Health Agency (Northern Ireland). 2011. Governance arrangements for research ethics committees: a harmonised edition. Available at: www.dh.gov.uk/en/Publicationsandstatistics/Publications/PublicationsPolicyAndGuidance/DH_126474 accessed 4th November 2011.

23. QAA. 2000. Code of practice for the assurance of academic quality and standards in higher education. Section 6: Assessment of Students. May 2000. Quality Assurance Agency for Higher Education. Gloucester.

24. Strauss, L. and Corbin, J. 1998. Basics of Qualitative Research. Techniques and Procedures for Developing Grounded Theory. Sage, London.

25. ENB .1997. An investigation into the reliability and validity of assessment strategies for the accreditation of prior learning of nurses, midwives and health visitors. Research Highlights, No.26. English National Board, for Nursing, Midwifery and Health Visiting. London.

26. Johnson, B. 2002. Models of APEL and Quality Assurance. Southern England Consortium for Credit Accumulation and Transfer., SEEC. Cravitz Printing Co. Ltd, Brentwood, Essex.

27. Babbie, E and Mouton, J. 2007. The practice of Social Research. $11^{\text {th }}$ edn. Oxford University Press, Cape Town.

28. Day, M. 2011. Developing Benchmarks for Prior Learning Assessment: An Holistic Approach to the Assessment of Prior Learning. In: NET2011. 22nd International Networking for Education in Healthcare Conference Churchill College University Cambridge 6-8 September 2011. 84.

29. Steffy, B. E. et.al. 2000. Life Cycle of the Career Teacher Sage. California.

30. Elliot. J.1992. Action Research for Educational Change. Philadelphia Open University Press, Milton Keynes.

31. Nixon, J. 2004. A Profession in Crisis? Chapter 31, In Hayes, D. Key Debates in Education. Routledge Falmer. London.

32. Sachs, J. 2003. The Activisit Teaching Profession. Open University Press. Buckingham.

33. SEEC 1995. A Quality Code for AP(E)L Issues for Managers and Practitioners. Proceedings of the SEEC National Conference. 6th December 1995. Southern England Consortium for Credit Accumulation and Transfer. Regents College, London.

34. Harris, J. 2000. RPL: Power, Pedagogy and Possibility. Human Sciences Research Council. Pretoria, South Africa. 
NOTES 